\title{
XLMR genes: update 2007
}

\author{
Pietro Chiurazzi ${ }^{\star, 1}$, Charles E Schwartz ${ }^{2}$, Jozef Gecz ${ }^{3,4}$ and Giovanni Neri ${ }^{\star, 1}$
}

\author{
${ }^{1}$ Institute of Medical Genetics, Catholic University, Rome, Italy; ${ }^{2}$ JC Self Research Institute of Human Genetics, \\ Greenwood Genetic Center, Greenwood, SC, USA; ${ }^{3}$ Department of Genetic Medicine, Women's and Children's Hospital, \\ Adelaide, South Australia, Australia; ${ }^{4}$ Department of Paediatrics, University of Adelaide, Adelaide, South Australia, \\ Australia
}

$\mathrm{X}$-linked mental retardation (XLMR) is a common cause of inherited intellectual disability with an estimated prevalence of $\sim 1 / 1000$ males. Most XLMR conditions are inherited as X-linked recessive traits, although female carriers may manifest usually milder symptoms. We have listed 215 XLMR conditions, subdivided according to their clinical presentation: 149 with specific clinical findings, including 98 syndromes and 51 neuromuscular conditions, and 66 nonspecific (MRX) forms. We also present a map of the 82 XLMR genes cloned to date (November 2007) and a map of the 97 conditions that have been positioned by linkage analysis or cytogenetic breakpoints. We briefly consider the molecular function of known XLMR proteins and discuss the possible strategies to identify the remaining XLMR genes. Final remarks are made on the natural history of XLMR conditions and on diagnostic issues.

European Journal of Human Genetics (2008) 16, 422-434; doi:10.1038/sj.ejhg.5201994; published online 16 January 2008

Keywords: mental retardation; chromosome X; XLMR conditions

\section{Introduction}

Mental retardation (MR) is a complex phenotype characterized by suboptimal functioning of the central nervous system (CNS) resulting in 'significant limitations both in intellectual functioning and in adaptive behavior as expressed in conceptual, social and practical adaptive skills,' originating before 18 years of age. ${ }^{1}$ It is estimated that from 1 to $3 \%$ of the general population is affected with MR. ${ }^{2,3}$ Increasingly, the term 'intellectual disability' is being used instead of 'mental retardation.' ${ }^{4} \mathrm{MR} /$ intellectual disability can be caused by genetic as well as environmental causes that act on the development and functioning of the CNS prenatally, perinatally or postnatally. ${ }^{5}$ Genetic causes of MR include chromosome aneusomies, chromosome structural abnormalities, genomic disorders and monogenic diseases. Such causes account

*Correspondence: Professor P Chiurazzi and Professor G Neri, Institute of Medical Genetics, Catholic University, Largo F. Vito 1, Rome 00168, Italy. Tel: + 3906 3054449; Fax: + 3906 3050031;

E-mails: pietro.chiurazzi@rm.unicatt.it and gneri@rm.unicatt.it

Received 25 August 2007; revised 28 November 2007; accepted 5 December 2007; published online 16 January 2008 for up to $50 \%$ of moderate-to-severe MR, while environmental factors (eg malnutrition, cultural deprivation) play a larger role in the pathogenesis of mild MR. ${ }^{6}$ An extended discussion of genes involved in the pathogenesis of MR has been recently provided by Inlow and Restifo ${ }^{6}$ and by Chelly et $a l^{7}{ }^{7}$ while Francis et $a l^{8}$ concentrated on genes underlying CNS malformations, which may cause MR and/ or epilepsy.

$\mathrm{X}$-linked mental retardation (XLMR) is a common cause of monogenic intellectual disability affecting mostly males, partly accounting for the higher prevalence of MR among males relative to females. ${ }^{9}$ However, female carriers may manifest (usually milder) symptoms, possibly because of skewed X-inactivation. ${ }^{10-11} \mathrm{~A}$ differential expression of $\mathrm{X}$-linked genes in males and females also appears to play a role in mental functioning, as discussed by Skuse. ${ }^{12} \mathrm{~A}$ prevalence of $1.83 / 1000$ males with XLMR had been estimated in 1980 by Herbst and Miller, ${ }^{13}$ with the fragile $\mathrm{X}$ syndrome being by far the most prevalent condition ( $\sim 20 \%$ of all XLMR cases). ${ }^{14}$ However, the finding of a much smaller contribution of individual genes, other than FMR1, to XLMR has recently led to a reduced prevalence estimate of $10-12 \%$ of all MR cases in males. ${ }^{15-17}$ 
This review represents the eight edition of the XLMR update, first compiled in 1990 by Neri et al. ${ }^{18}$ Tables and maps presented here are also available at the XLMR update web site (http://xlmr.interfree.it/home.htm) and complementary information can be found at the Greenwood Genetic Center web site (http://www.ggc.org/xlmr.htm).

Conditions listed in the present update have been identified either by searches of PubMed (http://www.pubmed. gov) or of the Online Mendelian Inheritance in Man (OMIM) database (http://www.ncbi.nlm.nih.gov/entrez/ query.fcgi? $d b=O M I M)$. Only few entries have been included based on conference abstracts.

It has been suggested that the concentration of genes causing MR (number of MR genes per megabase) may be twice as high on the $\mathrm{X}$ chromosome compared to autosomes. ${ }^{6}$ These estimates will be confirmed or disproved only when all MR genes will have been cloned. In any case, one should keep in mind that the identification of X-linked conditions is easier due to the hemizygosity of males, who inevitably manifest a phenotype when harboring a mutant allele. There is only one X-linked condition known that contradicts this inheritance pattern, that is, EFMR or epilepsy and MR limited to females. ${ }^{19}$ In this condition, heterozygous females are affected, while hemizygous males are apparently unaffected. The gene responsible for this condition and the mechanism leading to sparing of mutant males are still unknown.

\section{Nosology and classification}

Classification of MR can be based on the underlying causes (genetic, environmental or a combination thereof) and/or on their timing (pre-, peri- and postnatal), as discussed by Moog. ${ }^{20}$ A more practical subdivision is based on clinical presentation, irrespective of the identification of the causal gene or of the pathogenetic mechanism. In the first edition of the XLMR update, ${ }^{18}$ there was already a clinical distinction between specific and nonspecific conditions, the latter being characterized by MR only. Over the years, specific XLMR conditions were subdivided into four

Table 1 Count of XLMR conditions by clinical presentation: syndromes (listed in Supplementary Table S1), neuromuscular conditions (listed in Supplementary Table S2) and nonspecific/MRX conditions (listed in Supplementary Table S3)

\begin{tabular}{lccc}
\hline & Total count & Mapped & Cloned \\
\hline Syndromes & 98 & 31 & 38 \\
Neuromuscular & 51 & 16 & 28 \\
Nonspecific/MRX & 66 & 50 & 16 \\
Total conditions & 215 & 97 & 82 \\
\hline
\end{tabular}

For each category and for the total count, mapped conditions and cloned genes are also indicated. classes, ${ }^{21-26}$ namely (a) syndromes, with concurrent physical anomalies in various combinations, (b) neuromuscular conditions, with associated neurologic and/or muscular symptoms, (c) metabolic conditions and (d) dominant conditions. However, classes (c) and (d) are not based on a clinical presentation, but on the biochemical mechanism (c) or on the mode of inheritance (d). Furthermore, genes involved in causing dominant XLMR conditions (like MECP2) have often been found to cause Xlinked recessive conditions in some families. Therefore in this update, we decided to categorize XLMR conditions into three classes based on their clinical presentation: (a) syndromes, characterized by multiple congenital anomalies and defects in organs/tissues other than (but also including) the brain; (b) neuromuscular disorders, characterized by neurological or muscular symptoms (epilepsy, dystonia, spasticity, muscle weakness, and so on) but no malformations and (c) nonspecific conditions (MRX), where MR is the only consistent clinical manifestation among the affected individuals. ${ }^{27}$ This distinction has mostly practical value. Specific XLMR conditions (ie syndromes and neuromuscular conditions) can exist as separate nosological entities, recognizable on the basis of a distinctive clinical presentation, even if the causative gene or locus is unknown. On the contrary, nonspecific (MRX) conditions can only be distinguished based on the knowledge of their causative gene.

Table 1 summarizes all 215 XLMR conditions subdivided by clinical presentation and according to their mapping status (97 mapped and 82 cloned genes). Details on each condition are tabulated in Supplementary Tables S1-S3 (available online), where the total number of entries appears to be higher than 215 , because all allelic conditions are counted separately.

\section{Localization of XLMR genes and conditions}

Figure 1 contains an ideogram of the $\mathrm{X}$ chromosome with the position of the 82 known XLMR genes. All these genes carry mutations in at least a single family with multiple affected individuals. The three most recent genes were reported at the 13th International Workshop on Fragile X and XLMR and were associated with an Angelman-like syndrome (SLC9A6), ${ }^{28}$ with a neurological condition, that is, hyperekplexia and epilepsy (ARHGEF9) ${ }^{29-30}$ and with both a syndromic condition in one family (Supplementary Table S1, entry 95) and MRX in two families (HUWE1), ${ }^{31}$ respectively. Figures 2 and 3 illustrate the localization by linkage analysis or cytogenetic markers (translocation or inversion breakpoint, microdeletion or duplication) of mapped syndromes and neuromuscular conditions or MRX families, respectively. XLMR genes are spread over the entire $X$ chromosome with a higher density in two 


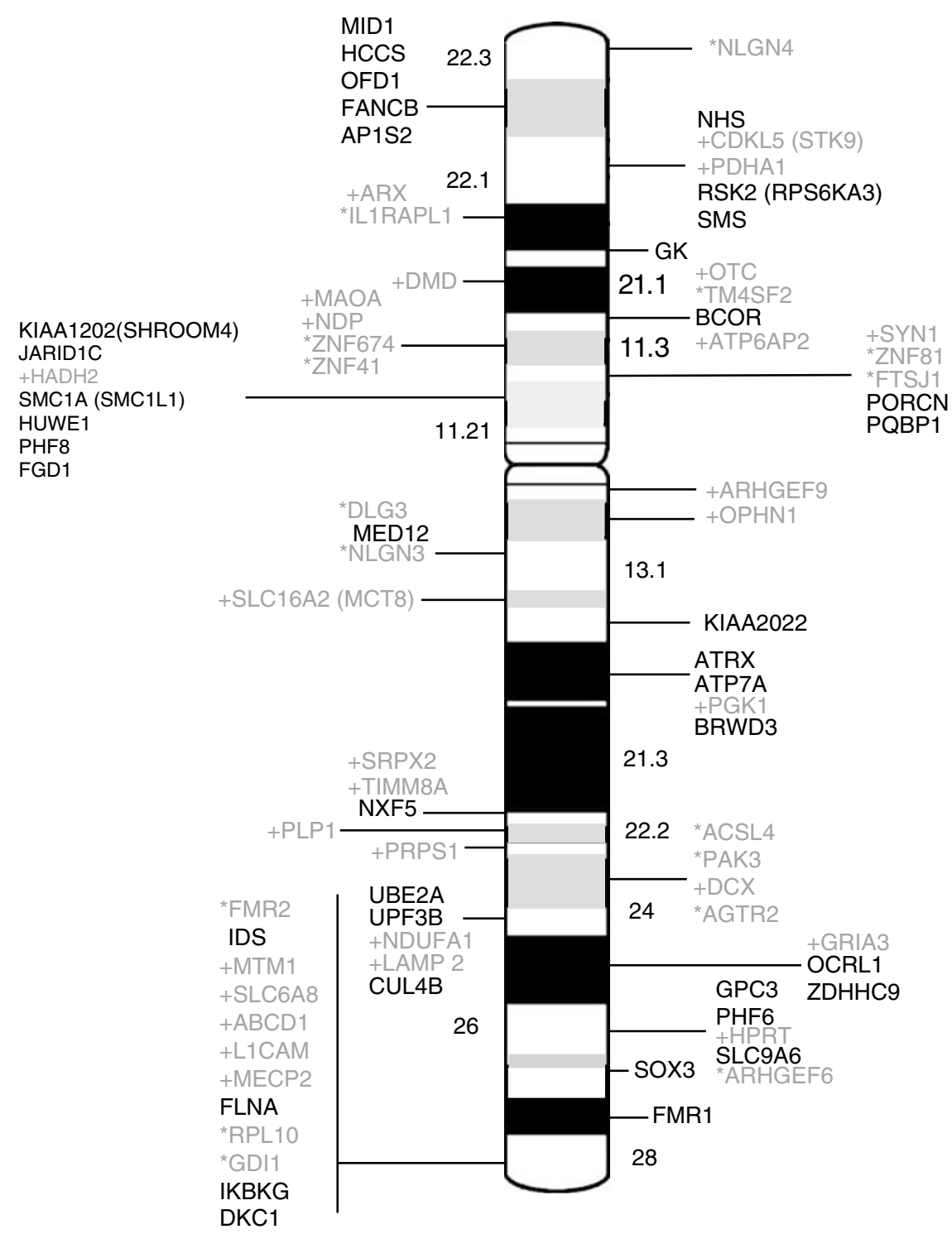

Figure 1 Ideogram of the X chromosome with the position of the 82 known XLMR genes. Genes written in black cause syndromes (Supplementary Table S1), those in gray preceded by a + sign cause neuromuscular disorders (Supplementary Table S2), while those written in gray preceded by an asterisk are involved in nonspecific (MRX) conditions (Supplementary Table S3).

G-negative bands at Xp11.2 (12 genes) and at Xq28 region (12 genes).

The actual role of a few XLMR genes is still uncertain because (a) they were identified in a single family with a missense mutation (eg CASK, EFHC2 and OST6), (b) they were found interrupted by the breakpoint of a balanced translocation or inversion in a single patient (eg KLF8 and $Z D H H C 15$ ) or (c) they were deleted together with other genes (eg ZNF673, ZNF630, SLC38A5 and BRAF2). Details on these unconfirmed candidate genes have been listed in Supplementary Table S4. Some of these were presented at the 13th International Workshop on Fragile X and XLMR held in Venice October 3-6, 2007.
Genomic duplications have also been identified in at least four different entries: (1) FG syndrome locus 5 in Supplementary Table S1 (OMIM \%300581; 5 Mb duplication in Xq22.3, including the PRPS1 and the MID2 genes); (2) panhypopituitarism in Supplementary Table S1 (OMIM \%312000; 1-4 Mb duplication in Xq26-q27 including the SOX3 gene); (3) Pelizaeus-Merzbacher disease in Supplementary Table S2 (OMIM \#312080; often due to small duplications encompassing the PLP1 gene) and (4) severe MR with hypotonia, progressive spasticity and recurrent infections (OMIM + 300005.0030). This latter clinical entity is listed in Supplementary Table S2 and has been identified in several XLMR families linked to 


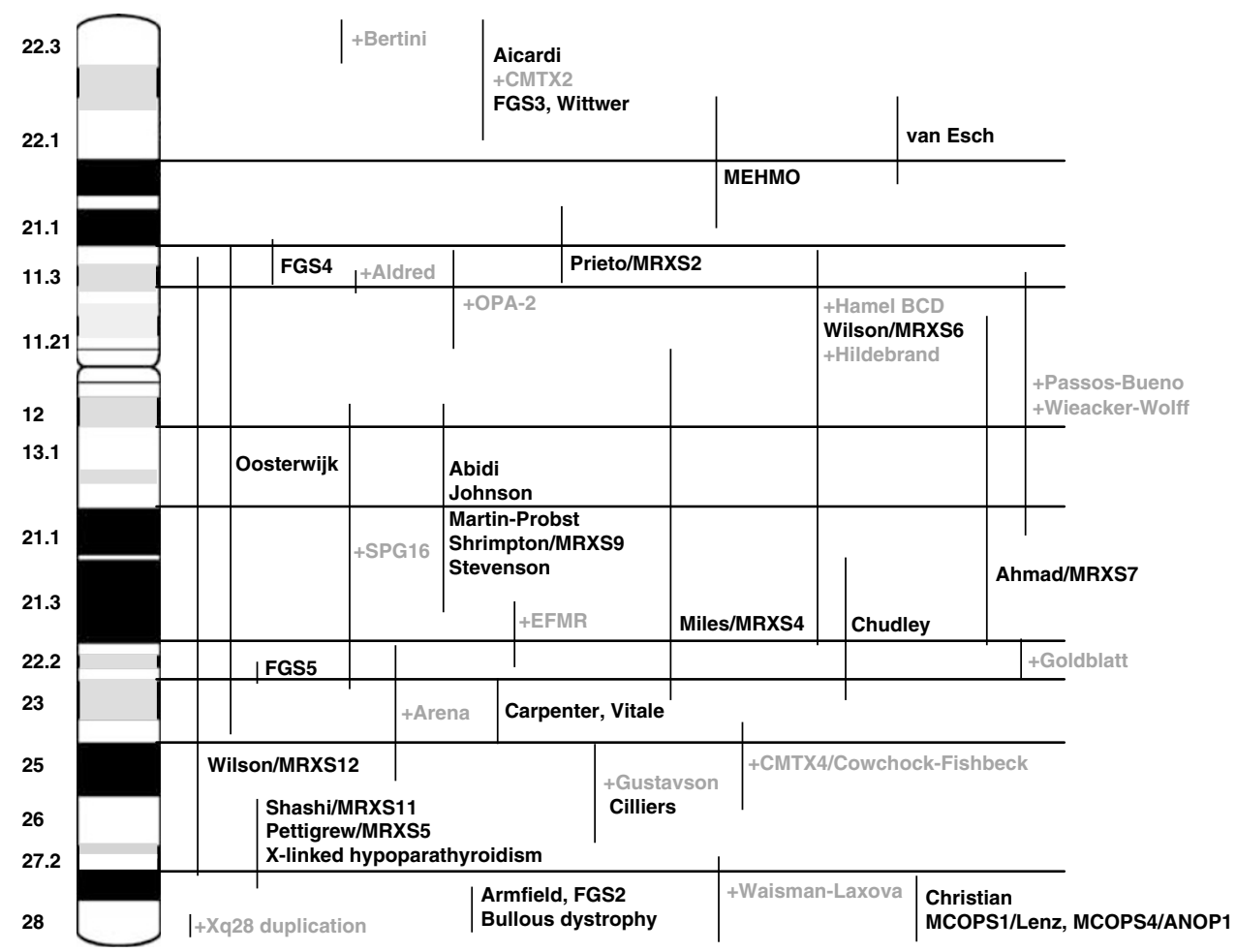

Figure 2 Ideogram of the $X$ chromosome with the position of the 47 specific conditions that were mapped on the $X$ chromosome. Vertical bars indicate the linkage/cytogenetic interval. The 31 syndromes are indicated in black (see Supplementary Table S1), while the 16 neuromuscular disorders are written in gray preceded by a + sign (see Supplementary Table S2).

Xq28. ${ }^{32-35}$ Although several other genes are included in the duplication, MECP2 is the only one to be present in all cases. ${ }^{33}$ Recent observations suggest that duplications are quite common in XLMR patients. ${ }^{36}$ For example, a recurrent duplication in $\mathrm{Xp} 11.22$ that harbors at least three genes (RIBC1, HADH2 and HUWE1) has been characterized by Froyen et $a l^{31}$ in six different pedigrees, including MRX17 and MRX31 (see Supplementary Table S3c). However, in such cases, the pathogenic role of individual genes included in the duplication is difficult to sort out. Functional studies and the establishment of animal models (eg mice overexpressing PLP ${ }^{37}$ ) will eventually clarify these issues.

\section{Molecular function of XLMR gene products}

Table 2 lists the 82 known XLMR genes, ordered by physical position on the $\mathrm{X}$ chromosome, that is, megabases from the Xp telomere. This table provides the name of the corresponding proteins as well as their subcellular localization and biological function, where known or predicted. Protein information was obtained partly from the Gene Ontology Web site (http://www.geneontology.org/) and partly from peer-reviewed publications. Figure 4 summarizes (a) the subcellular localization and (b) the biological function of XLMR gene protein products. These proteins can be found in all cell compartments: $30 \%$ in the nucleus, $28 \%$ in the cytoplasm and $16 \%$ in the organelles, while $22 \%$ are either membrane bound or secreted (Figure 4a). Their function is mainly related to signal transduction (19\%) and regulation of transcription (22\%), which may be considered the last step in the signaling cascade (Figure 4b). Many of the proteins indicated as 'membrane component' (15\%) are also likely to play a role in signal transduction. However, a relevant portion of XLMR proteins is involved in different biological pathways, such as core metabolism (15\%), DNA and RNA processing $(6 \%)$, protein synthesis $(3 \%)$, regulation of cell cycle and ubiquitin pathway (7\%). These fundamental processes may disproportionately affect cognition because of a brain-specific expression pattern of the corresponding genes. It is important to note that XLMR genes may be expressed in the brain but not in neurons; for example, PLP1 encodes for the proteolipid protein 1, a major component of myelin that is expressed exclusively in oligodendrocytes, that is, in the supporting cells belonging to the glia. ${ }^{37}$

The last column in Table 2 indicates whether a given protein localizes to synapses, according to data recently published by Laumonnier et $a l^{38}$ and also available at the Web site of the Genes to Cognition Programme of the Wellcome Trust (http://www.genes2cognition.org/). 


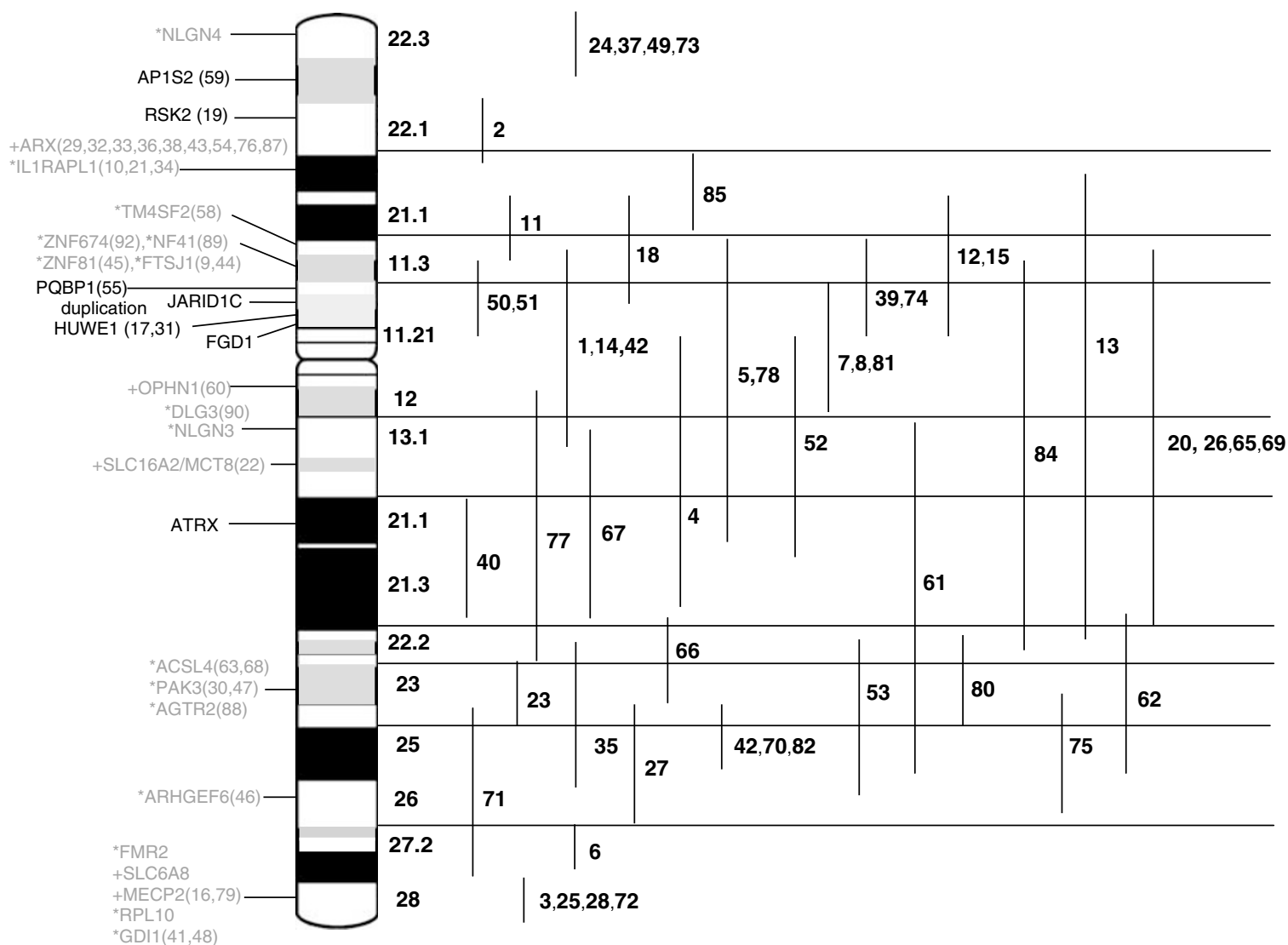

Figure 3 Ideogram of the $X$ chromosome with the position of the 50 MRX pedigrees with mapping information available (see Supplementary Table S3). Vertical bars indicate the linkage/cytogenetic intervals and numbers next to them correspond to individual MRX families/cases. Known MRX genes are indicated on the left side of the $\mathrm{X}$ chromosome and numbers in parentheses next to gene names correspond to the original MRX pedigrees.

Laumonnier et $a l^{38}$ list 39 proteins encoded by X-linked genes that belong to the synaptic proteome and indicate that 19 of these are known XLMR genes. It is important to note that, according to these authors, synaptosome preparations appear to include mitochondrial proteins (PDHA1 and HADH2), but surprisingly also a nuclear protein such as the DNA helicase ATRX. In contrast, some less represented transmembrane proteins may have gone undetected in the synaptic proteome (eg TM4SF2/TSPAN7) and were therefore not listed. One final note should be made about microRNAs (miRNA) and noncoding RNAs (ncRNA) transcribed by X-chromosomal loci, because their mutation may also potentially cause XLMR or other $\mathrm{X}$-linked inherited disorders. miRNA plays a role in controlling the expression of target genes at the post transcriptional level, and their deletion may affect the stability of several target RNA molecules. Chen et al ${ }^{39}$ selected 13 brain-expressed X-chromosomal miRNA genes and looked for mutations or deletions in a cohort of 464 XLMR patients. These authors identified only four nucleotide substitutions in the precursors of three miRNAs, but one was absent in the patient's affected brother and another one was found in 1 out of 183 normal control males, while two variants cosegregating with the disease in the third pedigree did not appear to have a significant effect on mir222 processing. ${ }^{39} \mathrm{Gecz}^{40}$ identified FMR3, a noncoding RNA transcribed from the same CpG island containing the promoter of the FMR2 gene, but in the opposite direction. Transcription of this ncRNA is also abolished in the presence of CCG triplet repeat expansion in patients expressing the FRAXE fragile site. ${ }^{40}$ Recently, while screening 441 Brazilian males with MR for FRAXE expansion, Santos-Reboucas et al $^{41}$ described a 58-bp deletion immediately distal to the CCG repeat that abolishes FMR3 but not FMR2 transcription, suggesting a role of this ncRNA in normal mental functioning. Currently, these miRNA and ncRNA genes, possibly involved in or contributing to $\mathrm{XLMR}$, are not listed in this catalogue.

\section{Strategies for candidate gene identification}

The search for XLMR genes is going to continue and it is difficult to estimate how many of the $\sim 900 \mathrm{X}$-linked protein-coding genes listed in the ENSEMBL database 
Table 2 Listing of the 82 known XLMR genes, ordered by physical distance (megabases) from the Xp telomere

\begin{tabular}{|c|c|c|c|c|c|c|c|}
\hline Gene name & $\begin{array}{l}\text { Megabases } \\
\text { from Xpter }\end{array}$ & Cytoband & OMIM & Protein name & Cellular component & Biological function & $\begin{array}{l}\text { Synaptic } \\
\text { localization }\end{array}$ \\
\hline $\begin{array}{l}\text { *NLGN4 } \\
\text { MID1 }\end{array}$ & $\begin{array}{c}5.82-6.15 \\
10.37-10.76\end{array}$ & $\begin{array}{l}\text { Xp22.32-.31 } \\
\text { Xp22.2 }\end{array}$ & $\begin{array}{l}* 300427 \\
* 300000\end{array}$ & $\begin{array}{l}\text { Neuroligin } 4 \\
\text { Midin (midline } 1 \text { protein) }\end{array}$ & $\begin{array}{l}\text { Membrane, plasma } \\
\text { Cytoplasm, } \\
\text { cytoskeleton }\end{array}$ & $\begin{array}{l}\text { Cell adhesion } \\
\text { Ubiquitin cycle, microtubule-associated complex }\end{array}$ & Yes \\
\hline HCCS & $11.03-11.05$ & Xp22.2 & *300056 & Holocytochrome C synthase & Mitochondrion & $\begin{array}{l}\text { Metabolism, energy production, cytochrome } c \\
\text { heme-lyase) }\end{array}$ & \\
\hline OFD1 & $13.66-13.69$ & Xp22.2 & *300170 & $\begin{array}{l}\text { Oral-facial-digital syndrome } 1 \\
\text { protein }\end{array}$ & Cytoplasm & Cytoskeleton, centrosome function & \\
\hline FANCB & $14.80-14.77$ & Xp22.2 & *300515 & $\begin{array}{l}\text { Fanconi anemia } \\
\text { complementation group } \\
\text { B protein }\end{array}$ & Nucleus & DNA repair & \\
\hline AP1S2 & $15.78-15.75$ & Xp22.2 & *300629 & $\begin{array}{l}\text { Adaptor-related protein } \\
\text { complex } 1 \text {, sigma } 2 \text { subunit }\end{array}$ & Cytoplasm, Golgi & $\begin{array}{l}\text { Membrane transporter-receptor mediated } \\
\text { endocytosis vesicle-mediated transport }\end{array}$ & \\
\hline $\begin{array}{l}\text { NHS } \\
+ \text { CDKL5/ } \\
\text { STK9 }\end{array}$ & $\begin{array}{l}17.30-17.66 \\
18.35-18.58\end{array}$ & $\begin{array}{l}\text { Xp22.2-22.13 } \\
\text { Xp22.13 }\end{array}$ & $\begin{array}{l}* 300457 \\
* 300203\end{array}$ & $\begin{array}{l}\text { Nance-Horan syndrome protein } \\
\text { cyclin-dependent kinase-like } 5\end{array}$ & $\begin{array}{l}\text { Nucleus } \\
\text { Nucleus? }\end{array}$ & $\begin{array}{l}\text { ? } \\
\text { Transcription regulation, serine/threonine kinase, } \\
\text { MECP2 phosphorylation }\end{array}$ & Yes \\
\hline +PDHA1 & $19.27-19.29$ & Xp22.12 & *312170 & $\begin{array}{l}\text { Pyruvate dehydrogenase } \\
\text { (lipoamide) } \alpha 1\end{array}$ & Mitochondrion & $\begin{array}{l}\text { Metabolism, glycolysis, acetyl-CoA, } \\
\text { oxidoreductase activity }\end{array}$ & Yes \\
\hline $\begin{array}{l}\text { RPS6KA3/ } \\
\text { RSK2 }\end{array}$ & $20.08-20.19$ & Xp22.12 & *300075 & $\begin{array}{l}\text { Ribosomal protein } \$ 6 \text { kinase, } \\
90 \mathrm{kDa} \text {, polypeptide } 3\end{array}$ & $\begin{array}{l}\text { Cytoplasm, } \\
\text { ribosome }\end{array}$ & $\begin{array}{l}\text { Signal transduction, protein serine/threonine } \\
\text { kinase }\end{array}$ & Yes \\
\hline SMS & $21.87-21.92$ & Xp22.11 & *300105 & spermine synthase & Cytoplasm? & $\begin{array}{l}\text { Metabolism, methionine metabolism, } \\
\text { polyamine metabolism }\end{array}$ & \\
\hline$+A R X$ & $24.93-24.94$ & Xp22.11 & *300382 & $\begin{array}{l}\text { Aristaless-related homeobox } \\
\text { protein }\end{array}$ & Nucleus & Transcription regulation & \\
\hline *IL1RAPL1 & $28.51-29.88$ & Xp21.2 & *300206 & $\begin{array}{l}\text { Interleukin } 1 \text { receptor accessory } \\
\text { protein-like } 1\end{array}$ & Membrane, plasma & Signal transduction & Yes \\
\hline GK & $30.58-30.66$ & $\mathrm{Xp} 21.2$ & *300474 & Glycerol 3-phosphotransferase & Mitochondrion & Metabolism, glycerol uptake & \\
\hline +DMD & $31.05-33.26$ & $\mathrm{Xp} 21.2-\mathrm{p} 21.1$ & *300377 & $\begin{array}{l}\text { Dystrophin (muscular dystrophy, } \\
\text { Duchenne and Becker types) }\end{array}$ & $\begin{array}{l}\text { Cytoplasm, } \\
\text { cytoskeleton }\end{array}$ & Cytoskeleton component, Dp260 & Yes \\
\hline +OTC & $38.10-38.16$ & Xp11.4 & *300461 & Ornithine carbamoyltransferase & Mitochondrion & Metabolism, urea cycle, amino acid & \\
\hline *TM4SF2 & $38.30-38.43$ & Xp11.4 & *300096 & Tetraspanin 7 & Membrane, plasma & $\begin{array}{l}\text { Membrane component, cell surface } \\
\text { glycoprotein }\end{array}$ & \\
\hline BCOR & $39.79-39.92$ & Xp11.4 & *300485 & BCL6 corepressor & Nucleus & $\begin{array}{l}\text { Transcription regulation, corepressor activity, } \\
\text { transcription factor and histone deacetylase } \\
\text { binding }\end{array}$ & \\
\hline +ATP6AP2 & $40.32-40.35$ & Xp11.4 & *300556 & $\begin{array}{l}\text { ATPase, } \mathrm{H}+\text { transporting, } \\
\text { lysosomal accessory protein } 2\end{array}$ & $\begin{array}{l}\text { Lysosome } \\
\text { membrane }\end{array}$ & Membrane transporter, lysosome & \\
\hline $\begin{array}{l}\text { +MAOA } \\
+\mathrm{NDP}\end{array}$ & $\begin{array}{l}43.40-43.49 \\
43.69-43.72\end{array}$ & $\begin{array}{l}\text { Xp11.3 } \\
\text { Xp11.3 }\end{array}$ & $\begin{array}{l}* 309850 \\
* 310600\end{array}$ & $\begin{array}{l}\text { Monoamine oxidase } \mathrm{A} \\
\text { Norrin (Norrie disease protein) }\end{array}$ & $\begin{array}{l}\text { Mitochondrion } \\
\text { Extracellular, } \\
\text { secreted }\end{array}$ & $\begin{array}{l}\text { Metabolism, neurotransmitter catabolism } \\
\text { Signal transduction, growth factor }\end{array}$ & Yes \\
\hline $\begin{array}{l}\text { *ZNF674 } \\
\text { *ZNF41 }\end{array}$ & $\begin{array}{l}46.29-46.24 \\
47.19-47.23\end{array}$ & $\begin{array}{l}\text { Xp11.3 } \\
\text { Xp11.3 }\end{array}$ & $\begin{array}{l}+300573 \\
* 314995\end{array}$ & $\begin{array}{l}\text { Zinc-finger protein } 674 \\
\text { Zinc-finger protein } 41\end{array}$ & $\begin{array}{l}\text { Nucleus } \\
\text { Nucleus }\end{array}$ & $\begin{array}{l}\text { Transcription regulation } \\
\text { Transcription regulation }\end{array}$ & \\
\hline+ SYN1 & $47.31-47.36$ & $X p 11.23$ & *313440 & Synapsin I & $\begin{array}{l}\text { Cytoplasm, } \\
\text { membrane }\end{array}$ & $\begin{array}{l}\text { Membrane transporter, neurotransmitter } \\
\text { exocytosis, actin binding, synaptic vesicle }\end{array}$ & Yes \\
\hline *ZNF81 & $47.58-47.66$ & Xp11.23 & *314998 & Zinc-finger protein 81 & $\begin{array}{l}\text { associated? } \\
\text { Nucleus }\end{array}$ & Transcription requlation & \\
\hline *FTSJ1 & $48.22-48.23$ & Xp11.23 & *300499 & Fts] homolog 1 & $\begin{array}{l}\text { (Nucleolus, } \\
\text { cytoplasm, } \\
\text { mitochondria)? }\end{array}$ & $\begin{array}{l}\text { Protein synthesis, rRNA processing, tRNA } \\
\text { processing, RNA methylation }\end{array}$ & \\
\hline PORCN & $48.25-48.26$ & Xp11.23 & *300651 & Drosophila porcupine homolog & $\begin{array}{l}\text { Cytoplasm, } \\
\text { endoplasmic } \\
\text { reticulum }\end{array}$ & $\begin{array}{l}\text { Wnt receptor signaling pathway, } \\
\text { Acyltransferase activity, integral to } \\
\text { membrane of endoplasmic reticulum }\end{array}$ & \\
\hline $\begin{array}{l}\text { PQBP1 } \\
\text { KIAA1202/ }\end{array}$ & $\begin{array}{c}48.64 \\
50.35-50.57\end{array}$ & $\begin{array}{l}X p 11.23 \\
\text { Xp11.22 }\end{array}$ & $\begin{array}{l}* 300463 \\
* 300579\end{array}$ & $\begin{array}{l}\text { Polyglutamine-binding protein } 1 \\
\text { KIAA1202 protein }\end{array}$ & $\begin{array}{l}\text { Nucleus } \\
\text { Cytoplasm? }\end{array}$ & $\begin{array}{l}\text { Transcription regulation } \\
\text { Cytoskeleton component, actin associated }\end{array}$ & \\
\hline
\end{tabular}




\begin{tabular}{|c|c|c|c|c|c|c|c|}
\hline Gene name & $\begin{array}{l}\text { Megabases } \\
\text { from Xpter }\end{array}$ & Cytoband & OMIM & Protein name & Cellular component & Biological function & $\begin{array}{l}\text { Synaptic } \\
\text { localization }\end{array}$ \\
\hline $\begin{array}{l}\text { JARID1C/ } \\
\text { SMCX }\end{array}$ & $53.24-53.27$ & Xp11.22 & *314690 & $\begin{array}{l}\text { Jumonji/ARID domain-containing } \\
\text { protein } 1 C\end{array}$ & Nucleus & $\begin{array}{l}\text { Transcriptionregulation, histone } \mathrm{H} 3-\mathrm{k} 4 \\
\text { demethylase }\end{array}$ & \\
\hline $\begin{array}{l}\text { SMC1A/ } \\
\text { SMC1L1 }\end{array}$ & $53.41-53.47$ & Xp11.22 & *300040 & $\begin{array}{l}\text { SMC1 structural maintenance of } \\
\text { chromosomes } 1 \text {-like } \\
1 \text { (yeast) }\end{array}$ & Nucleus & $\begin{array}{l}\text { Cell cycle, mitotic spindle organization and } \\
\text { biogenesis, chromosome segregation }\end{array}$ & \\
\hline$+\mathrm{HADH} 2$ & 53.47 & Xp11.22 & *300256 & $\begin{array}{l}\text { Hydroxyacyl-coenzyme A } \\
\text { dehydrogenase, type II }\end{array}$ & Mitochondrion & Metabolism, lipid metabolism & Yes \\
\hline HUWE1 & $53.74-53.56$ & Xp11.22 & - & $\begin{array}{l}\text { E3 ubiquitin-protein ligase } \\
\text { HUWE1 (UREB1, ARFBP1) }\end{array}$ & Cytoplasm & Ubiquitin-protein ligase, mRNA transport & \\
\hline $\begin{array}{l}\text { PHF8 } \\
\text { FGD1 }\end{array}$ & $\begin{array}{l}53.98-54.09 \\
54.48-54.54\end{array}$ & $\begin{array}{l}\text { Xp11.22 } \\
\text { Xp11.22 }\end{array}$ & $\begin{array}{l}* 300560 \\
* 305400\end{array}$ & $\begin{array}{l}\text { PHD finger protein } 8 \\
\text { FYVE, RhoGEF and PH } \\
\text { domain-containing protein } 1\end{array}$ & $\begin{array}{l}\text { Nucleus? } \\
\text { Cytoplasm }\end{array}$ & $\begin{array}{l}\text { Transcription regulation } \\
\text { Signal transduction, Rho guanyl-nucleotide } \\
\text { exchange factor activity }\end{array}$ & \\
\hline +ARHGEF9 & $62.92-62.77$ & $\mathrm{Xq11.2}$ & *300429 & $\begin{array}{l}\text { Cdc42 guanine nucleotide } \\
\text { exchange factor (GEF) } 9\end{array}$ & Cytoplasm & Regulation of Rho protein signal transduction & Yes \\
\hline$+\mathrm{OPHN} 1$ & $67.17-67.57$ & $\mathrm{Xq12}$ & *300127 & Oligophrenin 1 & Cytoplasm? & $\begin{array}{l}\text { Signal transduction, Rho GTPase activator } \\
\text { activity }\end{array}$ & \\
\hline *DLG3 & $69.58-69.64$ & Xq13.1 & *300189 & $\begin{array}{l}\text { Discs, large homolog } 3 \\
\text { (neuroendocrine-dlg, } \\
\text { Drosophila) }\end{array}$ & $\begin{array}{l}\text { Cytoplasm, } \\
\text { membrane } \\
\text { associated }\end{array}$ & Signal transduction, guanylate kinase activity & Yes \\
\hline $\begin{array}{l}\text { MED12/ } \\
\text { HOPA }\end{array}$ & $70.25-70.27$ & Xq13.1 & *300188 & $\begin{array}{l}\text { Mediator of RNA polymerase II } \\
\text { transcription, subunit } \\
12 \text { homolog }\end{array}$ & Nucleus & $\begin{array}{l}\text { Transcription regulation, RNA polymerase II } \\
\text { transcription mediator activity, } \\
\text { ligand-dependent nuclear receptor } \\
\text { transcription coactivator activity, } \\
\text { vitamin D receptor and thyroid } \\
\text { hormone receptor binding }\end{array}$ & \\
\hline *NLGN3 & $70.28-70.31$ & Xq13.1 & *300336 & Neuroligin 3 & Membrane, plasma & Cell adhesion & Yes \\
\hline $\begin{array}{l}+ \text { SLC16A2/ } \\
\text { MCT8 }\end{array}$ & $73.55-73.67$ & $\mathrm{Xq} 13.2$ & *300095 & $\begin{array}{l}\text { Solute carrier family } 16, \\
\text { member } 2 \text { (monocarboxylic } \\
\text { acid transporter } 8 \text { ) }\end{array}$ & Membrane, plasma & $\begin{array}{l}\text { Membrane transport, monocarboxylic acid } \\
\text { transporter activity }\end{array}$ & Tes \\
\hline KIAA2022 & $73.87-74.06$ & $\mathrm{Xq13.2}$ & *300524 & KIAA2022 protein & Nucleus? & $\begin{array}{l}\text { DNA synthesis, DNA polymerase activity, } \\
3^{\prime}-5^{\prime} \text { exonuclease activity }\end{array}$ & \\
\hline ATRX & $76.64-76.92$ & $\mathrm{Xq} 21.1$ & *300032 & $\begin{array}{l}\text { Alpha thalassemia/mental } \\
\text { retardation syndrome X } \\
\text { linked / X-linked helicase } 2\end{array}$ & Nucleus & $\begin{array}{l}\text { Transcription regulation, DNA repair, DNA } \\
\text { methylation, DNA recombination, DNA helicase }\end{array}$ & Yes \\
\hline ATP7A & $77.05-77.20$ & Xq21.1 & *300011 & $\begin{array}{l}\text { ATPase, Cu++ transporting, } \\
\text { alpha polypeptide }\end{array}$ & $\begin{array}{l}\text { Cytoplasm, Golgi, } \\
\text { endoplasmic } \\
\text { reticulum }\end{array}$ & $\begin{array}{l}\text { Membrane transporter, copper-exporting } \\
\text { ATPase activity }\end{array}$ & \\
\hline +PGK1 & $77.24-77.27$ & $\mathrm{Xq} 21.1$ & *311800 & Phosphoglycerate kinase 1 & Cytoplasm? & Metabolism, glycolysis, phosphokinase activity & \\
\hline BRWD3 & $79.95-79.81$ & $\mathrm{Xq} 21.1$ & *300553 & $\begin{array}{l}\text { Bromodomain and WD } \\
\text { repeat domain-containing } \\
\text { protein } 3\end{array}$ & Nucleus? & Transcription factor? & \\
\hline +SRPX2 & $99.78-99.81$ & $\mathrm{Xq} 22.1$ & *300642 & $\begin{array}{l}\text { Sushi-repeat-containing protein, } \\
\text { X-linked } 2\end{array}$ & $\begin{array}{l}\text { Extracellular, } \\
\text { secreted }\end{array}$ & Signal transduction, growth factor? & \\
\hline +TIMM8A & 100.49 & $\mathrm{Xq} 22.1$ & *300356 & $\begin{array}{l}\text { Translocase of inner } \\
\text { mitochondrial membrane } 8 \\
\text { homolog A }\end{array}$ & Mitochondrion & Membrane transporter, protein transport & \\
\hline NXF5 & $100.97-100.99$ & $\mathrm{Xq} 22.1$ & *300319 & Nuclear RNA export factor 5 & Nucleus, cytoplasm & $\begin{array}{l}\text { mRNA processing, mRNA export from } \\
\text { nucleus }\end{array}$ & \\
\hline +PLP & $102.91-102.93$ & $\mathrm{Xq} 22.2$ & *300401 & proteolipid protein 1 & Membrane, plasma & Membrane component, myelin component & Yes \\
\hline +PRPS1 & $106.76-106.78$ & Xq22.3 & *311850 & $\begin{array}{l}\text { Phosphoribosyl pyrophosphate } \\
\text { synthetase } 1\end{array}$ & Cytoplasm? & $\begin{array}{l}\text { Metabolism, ribonucleoside monophosphate } \\
\text { biosynthesis }\end{array}$ & Yes \\
\hline *ACSL4 & $108.77-108.86$ & $\mathrm{Xq} 23$ & *300157 & $\begin{array}{l}\text { Acyl-CoA synthetase long-chain } \\
\text { family member } 4\end{array}$ & $\begin{array}{l}\text { Peroxisome } \\
\text { membrane }\end{array}$ & Metabolism, lipid metabolism & \\
\hline *PAK3 & $110.23-110.35$ & $\mathrm{Xq} 23$ & *300142 & $\begin{array}{l}\text { P21 (CDKN1A)-activated } \\
\text { kinase } 3\end{array}$ & Cytoplasm? & $\begin{array}{l}\text { Signal transduction, protein serine/ } \\
\text { threonine kinase }\end{array}$ & \\
\hline
\end{tabular}




\begin{tabular}{|c|c|c|c|c|c|c|c|}
\hline Gene name & $\begin{array}{l}\text { Megabases } \\
\text { from Xpter }\end{array}$ & Cytoband & OMIM & Protein name & Cellular component & Biological function & $\begin{array}{l}\text { Synaptic } \\
\text { localization }\end{array}$ \\
\hline$+\mathrm{DCX}$ & $110.42-110.54$ & $\mathrm{Xq} 23$ & *300121 & $\begin{array}{l}\text { Doublecortin (doublecortex; } \\
\text { lissencephaly, X-linked) }\end{array}$ & $\begin{array}{l}\text { Cytoplasm, } \\
\text { cytoskeleton }\end{array}$ & $\begin{array}{l}\text { Cytoskeleton component, } \\
\text { microtubule-associated complex }\end{array}$ & \\
\hline *AGTR2 & 115.22 & $\mathrm{Xq} 23$ & *300034 & Angiotensin II receptor, type 2 & Membrane, plasma & $\begin{array}{l}\text { Signal transduction, G-protein-coupled } \\
\text { receptor protein signaling pathway }\end{array}$ & \\
\hline UBE2A & $118.59-118.60$ & $\mathrm{Xq} 24$ & *312180 & $\begin{array}{l}\text { Ubiquitin-conjugating enzyme } \\
\text { E2A (RAD6 homolog) }\end{array}$ & Nucleus & Ubiquitin cycle, ubiquitin-protein ligase & \\
\hline UPF3B & $118.87-118.85$ & $\mathrm{Xq} 24$ & *300298 & $\begin{array}{l}\text { UPF3 regulator of nonsense } \\
\text { transcripts homolog B }\end{array}$ & Nucleus, cytoplasm & mRNA catabolism, nonsense-mediated decay & \\
\hline +NDUFA1 & 118.89 & $\mathrm{Xq} 24$ & *300078 & $\begin{array}{l}\text { NADH dehydrogenase } \\
\text { (ubiquinone) } 1 \alpha \text { subcomplex }\end{array}$ & Mitochondrion & $\begin{array}{l}\text { Metabolism, energy production, } \\
\text { oxidoreductase activity }\end{array}$ & \\
\hline +LAMP2 & $119.44-119.48$ & $\mathrm{Xq} 24$ & *309060 & $\begin{array}{l}\text { Lysosomal-associated membrane } \\
\text { protein } 2\end{array}$ & $\begin{array}{l}\text { Lysosome } \\
\text { membrane }\end{array}$ & Membrane, lysosome & \\
\hline CUL4B & $119.59-119.54$ & $\mathrm{Xq} 24$ & *300304 & Cullin 4B & Nucleus? & Cell cycle, ubiquitin cycle, E3 ubiquitin ligase & \\
\hline +GRIA3 & $122.14-122.45$ & $\mathrm{Xq} 25$ & *305915 & $\begin{array}{l}\text { Glutamate receptor ionotropic } \\
\text { AMPA } 3\end{array}$ & Membrane, plasma & $\begin{array}{l}\text { Signal transduction, ion transport, glutamate } \\
\text { signaling pathway }\end{array}$ & Yes \\
\hline OCRL1 & $128.50-128.55$ & $\mathrm{Xq} 25$ & *309000 & $\begin{array}{l}\text { Phosphatidylinositol } \\
\text { polvphosphate 5-phosphatase }\end{array}$ & Cytoplasm, Golgi & Signal transduction, lipid metabolism & \\
\hline ZDHHC9 & $128.80-128.76$ & $X q 25-X q 26.1$ & *300646 & $\begin{array}{l}\text { Zinc-finger, DHHC-domain- } \\
\text { containing protein } 9\end{array}$ & $\begin{array}{l}\text { Cytoplasm, } \\
\text { endoplasmic } \\
\text { reticulum }\end{array}$ & $?$ & \\
\hline GPC3 & $132.49-132.95$ & $\mathrm{Xq} 26.2$ & *300037 & Glypican 3 & Extracellular, matrix & $\begin{array}{l}\text { Membrane component, integral membrane } \\
\text { proteoglycan }\end{array}$ & \\
\hline PHF6 & $133.33-133.39$ & $\mathrm{Xq} 26.2$ & *300414 & PHD finger protein 6 & Nucleus & Transcription regulation & \\
\hline+ HPRT & $133.42-133.46$ & $\mathrm{Xq} 26.2$ & $* 308000$ & $\begin{array}{l}\text { Hypoxanthine } \\
\text { phosphoribosyltransferase } 1\end{array}$ & Cytoplasm & Metabolism, purine ribonucleoside salvage & \\
\hline SLC9A6 & $134.88-134.95$ & $X q 26.3$ & *300231 & $\begin{array}{l}\text { Solute carrier family } 9 \\
\text { member } 6 \text {, sodium/ } \\
\text { hydrogen exchanger } 6 \text { (NHE6) }\end{array}$ & $\begin{array}{l}\text { Endoplasmic } \\
\text { reticulum, } \\
\text { mitochondrion }\end{array}$ & $\begin{array}{l}\text { Sodium:hydrogen antiporter activity, lysosome } \\
\text { organization and biogenesis, regulation of } \\
\text { endosome volume }\end{array}$ & \\
\hline *ARHGEF6 & $135.57-135.69$ & $X q 26.3$ & *300267 & $\begin{array}{l}\text { Rac/Cdc42 guanine nucleotide } \\
\text { exchange factor (GEF) } 6\end{array}$ & Cytoplasm & $\begin{array}{l}\text { Signal transduction, Rho guanyl-nucleotide } \\
\text { exchange factor activity }\end{array}$ & \\
\hline SOX3 & 139.41 & $\mathrm{Xq} 27.1$ & *313430 & SRY (sex determining region Y)- & Nucleus & Transcription regulation & \\
\hline FMR1 & $146.80-146.84$ & $\mathrm{Xq} 27.3$ & *309550 & $\begin{array}{l}\text { Fragile X mental retardation } \\
\text { protein } 1 \text { (FMRP) }\end{array}$ & Nucleus, cytoplasm & mRNA processing, mRNA export from nucleus & \\
\hline *FMR2 & $147.39-147.89$ & $\mathrm{Xq} 28$ & *309548 & $\begin{array}{l}\text { AF4/FMR2 family, member } 2 \\
\text { protein }\end{array}$ & Nucleus & Transcription regulation & \\
\hline & $148.36-148.39$ & $\mathrm{Xq} 28$ & *309900 & $\begin{array}{l}\text { protein } \\
\text { Iduronate 2-sulfatase }\end{array}$ & Lysosome & Metabolism, glycosaminoglycan metabolism & \\
\hline +MTM1 & $149.49-149.59$ & $\mathrm{Xq} 28$ & *300415 & Myotubularin 1 & $\begin{array}{l}\text { Cytoplasm, } \\
\text { membrane } \\
\text { associated? }\end{array}$ & $\begin{array}{l}\text { Signal transduction, protein phosphatase, } \\
\text { phosphatidylinositol phosphatase activity, } \\
\text { protein serine/threonine phosphatase activity, } \\
\text { protein tyrosine phosphatase activity }\end{array}$ & \\
\hline +SLC6A8 & $152.43-152.61$ & $\mathrm{Xq} 28$ & *300036 & $\begin{array}{l}\text { Solute carrier family } 6 \\
\text { (neurotransmitter transporter, } \\
\text { creatine), member } 8\end{array}$ & Membrane, plasma & $\begin{array}{l}\text { Membrane transport, creatine:sodium } \\
\text { symporter activity, neurotransmitter:sodium } \\
\text { symporter activity }\end{array}$ & \\
\hline$+A B C D 1$ & $152.64-152.66$ & $\mathrm{Xq} 28$ & *300371 & $\begin{array}{l}\text { ATP-binding cassette, } \\
\text { subfamily D (ALD), } \\
\text { member } 1\end{array}$ & $\begin{array}{l}\text { Peroxisome } \\
\text { membrane }\end{array}$ & Membrane transporter, peroxisome & \\
\hline+ L1CAM & $152.78-152.80$ & $\mathrm{Xq} 28$ & *308840 & L1 cell adhesion molecule & Membrane, plasma & Cell adhesion & Yes \\
\hline +MECP2 & $152.94-153.02$ & $\mathrm{Xq} 28$ & *300005 & Methyl CpG-binding protein 2 & Nucleus & $\begin{array}{l}\text { Transcription regulation, methylcytosine } \\
\text { binding }\end{array}$ & \\
\hline FLNA & $153.23-153.25$ & $\mathrm{Xq} 28$ & *300017 & $\begin{array}{l}\text { Filamin A, alpha (actin-binding } \\
\text { protein } 280 \text { ) }\end{array}$ & $\begin{array}{l}\text { Cytoplasm, } \\
\text { cytoskeleton }\end{array}$ & $\begin{array}{l}\text { Signal transduction, actin cytoskeleton, } \\
\text { cell motility, positive regulation of } \\
\mathrm{I}-\kappa \mathrm{B} \text { kinase/NF-KB cascade }\end{array}$ & Yes \\
\hline
\end{tabular}


Table 2 (Continued)

\begin{tabular}{|c|c|c|c|c|c|c|c|}
\hline Gene name & $\begin{array}{l}\text { Megabases } \\
\text { from Xpter }\end{array}$ & Cytoband & OMIM & Protein name & Cellular component & Biological function & $\begin{array}{l}\text { Synaptic } \\
\text { localization }\end{array}$ \\
\hline *RPL10 & $153.27-153.28$ & $\mathrm{Xq} 28$ & *312173 & Ribosomal protein L10 & $\begin{array}{l}\text { Cytoplasm, } \\
\text { ribosome }\end{array}$ & Protein synthesis, ribosomal protein & Yes \\
\hline *GDI1 & 153.32 & $\mathrm{Xq28}$ & *300104 & GDP dissociation inhibitor 1 & $\begin{array}{l}\text { Cytoplasm, } \\
\text { membrane } \\
\text { associated }\end{array}$ & $\begin{array}{l}\text { Signal transduction, regulation of GTPase } \\
\text { activity }\end{array}$ & Yes \\
\hline IKBKG & $153.42-153.44$ & $\mathrm{Xq28}$ & *300248 & $\begin{array}{l}\text { Inhibitor of } \kappa \text { light polypeptide } \\
\text { gene enhancer in B cells, kinase } \\
\text { gamma }\end{array}$ & Nucleus & $\begin{array}{l}\text { Transcription regulation, induction of } \\
\text { apoptosis, immune response, } \mathrm{I}-\kappa \mathrm{B} \\
\text { kinase/NF- } \kappa \mathrm{B} \text { cascade }\end{array}$ & \\
\hline DKC1 & $153.64-153.66$ & $\mathrm{Xq} 28$ & *300126 & Dyskerin & Nucleus & $\begin{array}{l}\text { Cell cycle, rRNA processing, telomere } \\
\text { maintenance via telomerase }\end{array}$ & \\
\hline
\end{tabular}

Genes whose symbol is preceded by a + sign are involved in neuromuscular disorders (Supplementary Table S2), while those with an asterisk are involved in nonspecific (MRX) conditions (Supplementary Table S3). All other genes are involved in XLMR syndromes (Supplementary Table S1). Cytogenetic localization and the gene's OMIM number are indicated in columns 3 and 4 , respectively. The name of the corresponding protein, its subcellular localization, biological function and eventual synaptic localization are reported in columns $5-8$. ${ }^{*}$ These genes are involved in nonspecific (MRX) conditions (column 1).
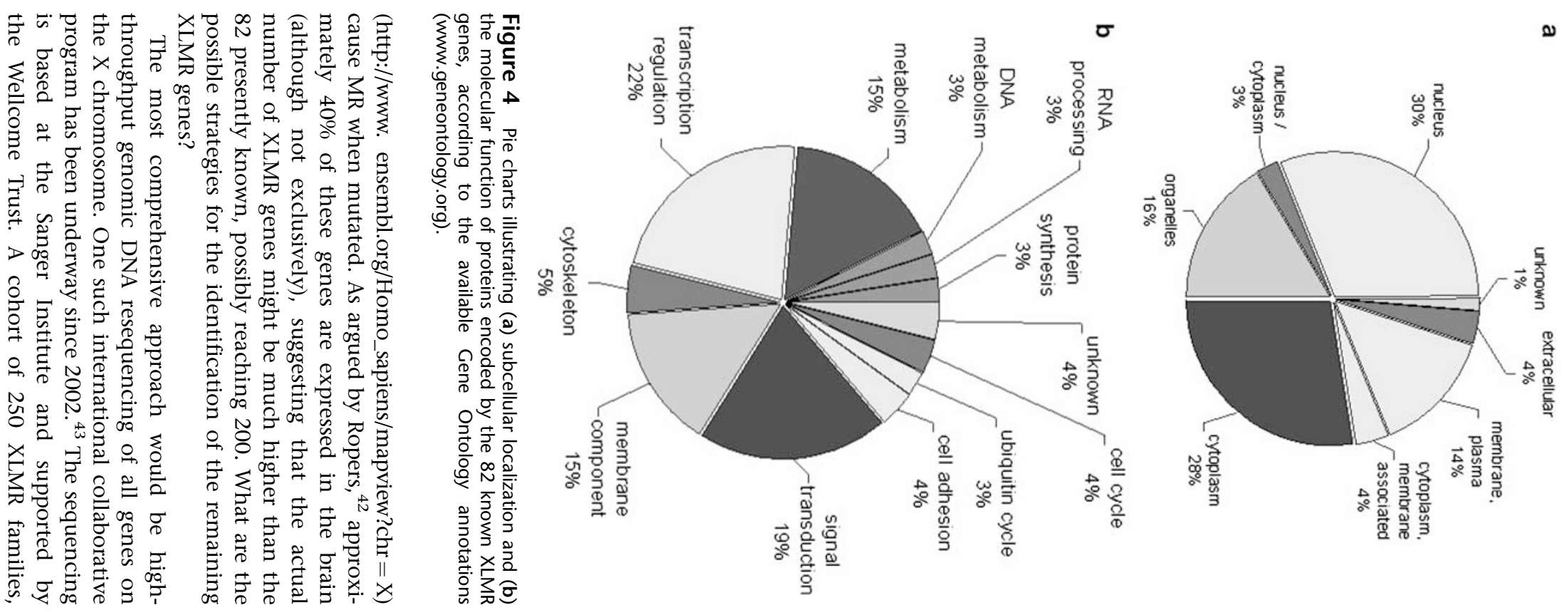
contributed by groups at Cambridge University (UK), Greenwood Genetic Center (USA) and Newcastle and Adelaide University (Australia), is utilized as starting material. Since 2004, this international collaboration has identified eight XLMR genes (DLG3, AP1S2, CUL4B, MED12, ZDHHC9, BRWD3, UPF3B and HUWE1).

A mutational screening of 47 brain-expressed genes from a $7.4 \mathrm{Mb}$ region in Xp11 was undertaken by the EuroMRX consortium $^{44}$ and since 2003 it has led to the identification of four genes (FTSJ1, JARID1C, PQBP1 and PHF8). However, such high-throughput resequencing approaches have their pitfalls and there are no guarantees that all or even the majority of mutations will be identified. The associated high cost, quality of the clinical material as well as the nature (eg duplications) and position (eg outside the coding regions) of the mutation are among the major complications. A candidate gene approach may provide a more focused alternative. Potential candidate genes might belong to at least three categories: (1) genes that are highly expressed in the brain (although many XLMR genes have a fairly 'flat' expression profile, ie they are transcribed at similar levels in several different tissues); (2) paralogues of known XLMR genes, because the corresponding proteins may have similar function (eg NLGN4 and NLGN3); (3) genes encoding proteins that interact with known XLMR proteins, because they cooperate in the same molecular pathways for example, members of the synaptic proteome such as those listed by Laumonnier et al. ${ }^{38}$ However, the protein encoded by a known XLMR gene may also interact with the mRNA of other target genes, as recently described for FMRP and the PSD95 mRNA. ${ }^{45}$ Therefore, the third criterion might be extended to include genes encoding proteins and/or mRNAs that interact with known XLMR proteins. The three above-mentioned criteria might also be used for selecting autosomal genes potentially involved in inherited MR. For example, the gene encoding the PSD95/ SAP90 protein is DLG4, a paralogue of the XLMR gene $D L G 3$. This gene is located on chromosome $17 \mathrm{p}$ and represents a potential candidate gene for autosomal MR.

The identification of a chromosome abnormality, such as a reciprocal translocation or a cryptic (submicroscopic) deletion or duplication, may also be extremely helpful in localizing a candidate gene, even in sporadic cases. Subtelomeric translocations have been identified by FISH analysis in up to $5 \%$ of patients with a family history of MR and dysmorphic features. ${ }^{46}$ More recently, application of array technology to perform comparative genome hybridization (array-CGH) has allowed detection of submicroscopic deletions and duplications that would have been missed by both standard karyotyping and subtelomeric FISH. ${ }^{4-48}$ Array-CGH can be performed at different resolution, that is, $\sim 3400$ BAC clones may be evenly spaced across the human genome every $1 \mathrm{Mb}^{48}$ or more clones $(\sim 32000)$ can be tiled up, providing a resolution of $100 \mathrm{~kb}^{47}$
Lugtenberg et al $^{49}$ have prepared a specific array with 1460 BAC clones spanning the $X$ chromosome $(100 \mathrm{~kb}$ resolution) and tested probands from $40 \mathrm{MRX}$ families, finding one family with a $7 \mathrm{Mb}$ duplication in Xp22.2 and two families with a $500 \mathrm{~kb}$ duplication in Xq28 encompassing the MECP2 gene. An even higher resolution is offered by the oligonucleotide arrays such as those employed by Friedman et $a l,{ }^{50}$ who studied 100 children with idiopathic MR. These authors used the Affymetrix GeneChip Human Mapping 100K SNP arrays and found eight cases of de novo deletions (as small as $178 \mathrm{~kb}$ ) and two cases of de novo duplications (as small as $1.1 \mathrm{Mb}$ ).

It is important to note that no single technique can substitute for all the others. Balanced translocations that interrupt a given XLMR gene can be identified by standard karyotyping (or subtelomeric FISH), but would go undetected with array-CGH and genomic sequencing. Conversely, submicroscopic duplications may be identified by array-CGH but would be missed with subtelomeric FISH and sequencing. Microdeletions would be readily detected by sequencing in hemizygous males but array-CGH and SNP arrays can identify small deletions also on the autosomes.

Zhang et $\mathrm{al}^{51}$ have developed a cDNA array with $\sim 1700$ ESTs corresponding to most protein-coding genes on the $\mathrm{X}$ chromosome. Such an array has the potential to detect the presence of mutations in the regulatory region of genes that will result in significantly altered (usually decreased) gene expression levels. These mutations would not be detected by sequencing of the entire open reading frame of the gene. By analyzing the cDNA of 43 probands belonging to independent XLMR families, Zhang et $a l^{51}$ found two patients with a fourfold reduction in the expression of the PLP2 gene and of the corresponding protein and identified the same point mutation in the promoter, segregating with MR and altering the binding sequence of transcription factor ELK1.

\section{Natural history of the XLMR catalogue}

Thirty-nine conditions were listed in the first edition of the catalogue, $^{18} 17$ had been localized by linkage analysis and no XLMR gene had been identified yet. The FMR1 gene, which is inactivated in the fragile $X$ syndrome and was the first gene responsible for XLMR to be cloned, was discovered just few months later.

Figure 5 illustrates the numbers of XLMR conditions (total, mapped and cloned) at different intervals over the last 17 years (1990-2007). The total number of entries has reached a plateau around 200, but this is not due to the absence of new reports of X-linked families and clinical entities. It rather reflects a balance between the new entries and those that are 'lumped' together because they were shown to have a mutation in the same gene. In contrast, 


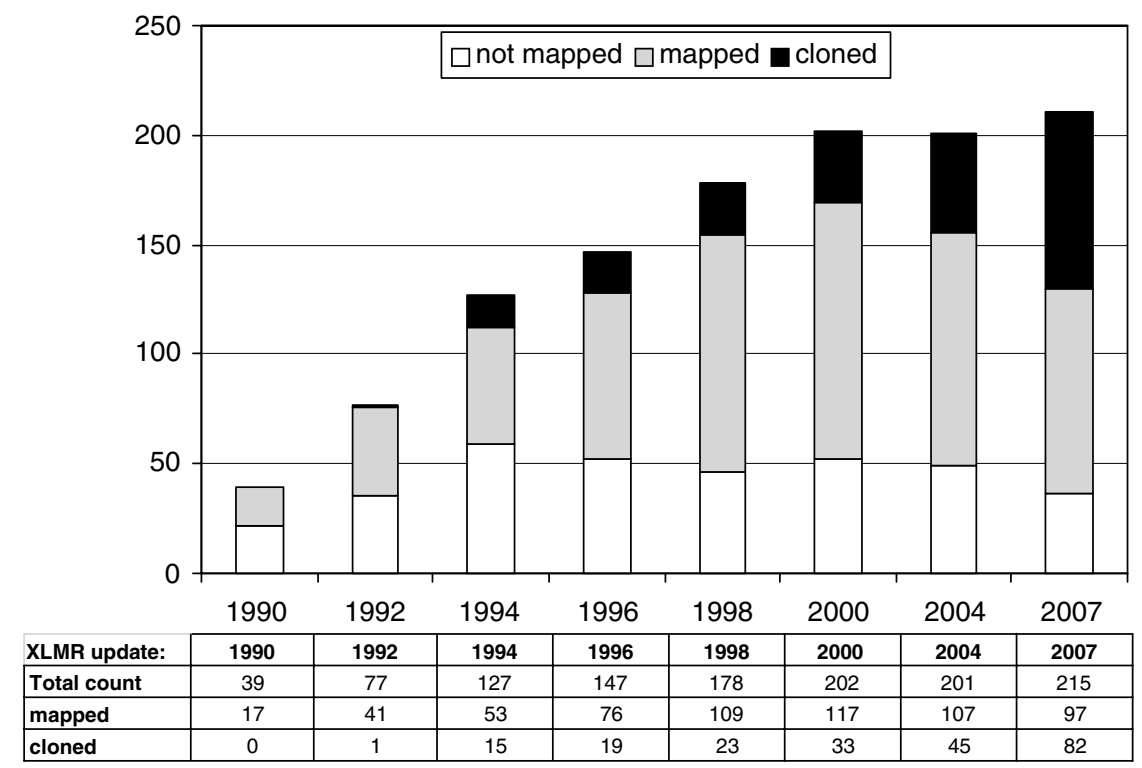

Figure 5 Bar chart illustrating the historical progress in the identification of X-linked MR conditions as listed in the various XLMR updates since 1990. The total number of conditions has apparently reached a plateau in 2000, while the number of cloned genes (black) continue to increase at the expense of mapped (gray) and unmapped (white) XLMR conditions. The total number of catalogue entries, of mapped conditions and of cloned XLMR genes is also tabulated.

the number of cloned genes has more than doubled since 2001 and the number of conditions without a gene or at least a locus has decreased to less than $20 \%$ of the total number. Some of these latter conditions have been described more than 20 years ago and no sources of DNA might be currently available. Therefore, these 'orphan' entries might never be linked to known XLMR genes unless clinicians contact the families again and establish cell lines to secure a reliable source of DNA and RNA from the index cases. This is obviously true also for every new family identified and reported today.

The natural history of XLMR conditions has thus changed over the last 17 years: while linkage studies on large pedigrees assisted in mapping well-characterized clinical conditions on the $\mathrm{X}$ chromosome and candidate gene screening was slowly conducted, nowadays candidate genes abound and large numbers of patients (familial as well as isolated cases) are being screened in search of mutations.

\section{Diagnostic issues}

Approximately $50 \%$ of children with MR referred to a tertiary care center will receive a causal diagnosis, with clinical history and physical examination being the first and most important steps in the diagnostic process. ${ }^{52}$ Consensus recommendations on the evaluation of individuals and children with MR have been prepared by the American College of Medical Genetics ${ }^{53}$ and by the Genetics Committee of the American Academy of
Pediatrics. ${ }^{54}$ Useful flowcharts for diagnostic procedures have also been provided by Battaglia and Carey ${ }^{55}$ and van Karnebeek et al. ${ }^{56}$ This latter review provides an evidencebased information on the usefulness of various diagnostic procedures and is adaptable to the evaluation of potential XLMR patients. Briefly, collection of family history and physical examination (including a dysmorphological and neurological evaluation) are mandatory for every proband. Standard cytogenetic studies should then be performed unless a different cause is already suspected, while FISH analysis for subtelomeric rearrangements may be restricted to a subset of patients with dysmorphic features and/or positive family history. Array-CGH for the identification of cryptic deletions/duplications would represent a further step and may become increasingly common as the price of (micro)arrays decreases. Molecular testing for fragile $\mathrm{X}$ syndrome should also be done on all boys and girls lacking another diagnosis, while testing for the $A R X$ recurrent mutation (dup24bp) can be added in the presence of epilepsy and/or dystonia. ${ }^{57}$ Search for duplication of the MECP2 region may be warranted in any male with congenital hypotonia and significant delay. ${ }^{34}$ Molecular testing for other XLMR genes might be more cost-effective in the presence of positive family history with convincing evidence of $\mathrm{X}$ linkage, ${ }^{58}$ unless future technological advances (eg use of DNA resequencing chips for all known XLMR genes) will lower the costs of mutational analysis. Neuroimaging studies (NMR/MRI) to confirm or exclude the presence of brain malformations should be reserved to patients with neurological symptoms, such as epilepsy, micro/macrocephaly and/or associated manifestations for 
example, phacomatosis. ${ }^{59}$ Finally, simple tests of urine, blood and cerebrospinal fluid may lead to a diagnosis of a metabolic disorder, even in the absence of clear dysmorphic features or neurological symptoms like epilepsy. ${ }^{60}$ Metabolic brain imaging (magnetic resonance spectroscopy) has also helped to uncover biochemical abnormalities within the brain, such as a deficit of the creatine transporter encoded by the $S L C 6 A 8$ gene. Creatine transporter deficiency has been recently suggested to account for $1 \%$ of males with MR of unknown etiology ${ }^{61}$ and can be easily suspected in the presence of an increased creatine/creatinine ratio in urine. It goes without saying that in the clinical practice the diagnostic approach will result from a balance between the opinion of the expert clinician, the available means and the affordable costs. Patients and families will have to be involved in a comprehensive genetic counseling leading them to understand the possibilities, but also the limits, of current clinical and molecular genetics.

\section{Acknowledgements}

This work has been supported in part by TELETHON grant (GGP06224), PRIN 2005 grant (no.2005060575) and a Conquer Fragile X Foundation grant to GN.; and by Grant HD26202 from NICHD and by the South Carolina Department of Disabilities and Special Needs to CES. This paper is dedicated to the memory of Libor Kozák (1960-2007) and of Ethan Francis Schwartz (1996-1998).

\section{References}

1 Luckasson R, Borthwick-Duffy S, Buntinx WHE et al: Mental Retardation: Definition, Classification, and Systems of Supports 10th edn. American Association on Mental Retardation: Washington, DC, 2002.

2 Larson SA, Lakin KC, Anderson L, Kwak N, Lee JH, Anderson D: Prevalence of mental retardation and developmental disabilities: estimates from the 1994/1995 National Health Interview Survey Disability Supplements. Am J Ment Retard 2001; 106: 231-252.

3 Brosco JP, Mattingly M, Sanders LM: Impact of specific medical interventions on reducing the prevalence of mental retardation. Arch Pediatr Adolesc Med 2006; 160: 302-309.

4 Schalock RL, Luckasson RA, Shogren KA et al: The renaming of mental retardation: understanding the change to the term intellectual disability. Intellect Dev Disabil 2007; 45: 116-124.

5 Chiurazzi P, Oostra BA: Genetics of mental retardation. Curr Opin Pediatr 2000; 12: 529-535.

6 Inlow JK, Restifo LL: Molecular and comparative genetics of mental retardation. Genetics 2004; 166: 835-881.

7 Chelly J, Khelfaoui M, Francis F, Cherif B, Bienvenu T: Genetics and pathophysiology of mental retardation. Eur J Hum Genet 2006; 14: 701-713.

8 Francis F, Meyer G, Fallet-Bianco C et al: Human disorders of cortical development: from past to present. Eur J Neurosci 2006; 23: 877-893.

9 Lehrke R: Theory of X-linkage of major intellectual traits. Am J Ment Defic 1972; 76: 611-619.

10 Plenge RM, Stevenson RA, Lubs HA, Schwartz CE, Willard HF: Skewed X-chromosome inactivation is a common feature of X-linked mental retardation disorders. Am J Hum Genet 2002; 71: $168-173$.
11 Amos-Landgraf JM, Cottle A, Plenge RM et al: X chromosomeinactivation patterns of 1,005 phenotypically unaffected females. Am J Hum Genet 2006; 79: 493-499.

12 Skuse DH: X-linked genes and mental functioning. Hum Mol Genet 2005; 14: R27-R32.

13 Herbst DS, Miller JR: Nonspecific X-linked mental retardation II: the frequency in British Columbia. Am J Med Genet 1980; 7: $461-469$.

14 Fishburn J, Turner G, Daniel A, Brookwell R: The diagnosis and frequency of X-linked conditions in a cohort of moderately retarded males with affected brothers. Am J Med Genet 1983; 14: $713-724$.

15 Mandel JL, Chelly J: Monogenic X-linked mental retardation: is it as frequent as currently estimated? The paradox of the ARX (Aristaless X) mutations. Eur J Hum Genet 2004; 12: 689-693.

16 Ropers HH, Hamel BC: X-linked mental retardation. Nat Rev Genet 2005; 6: 46-57.

17 Kleefstra T, Hamel BC: X-linked mental retardation: further lumping, splitting and emerging phenotypes. Clin Genet 2005; 67: $451-467$.

18 Neri G, Gurrieri F, Gal A, Lubs HA: XLMR genes: update 1990. Am J Med Genet 1991; 38: 186-189.

19 Ryan SG, Chance PF, Zou CH, Spinner NB, Golden JA, Smietana S Epilepsy and mental retardation limited to females: an X-linked dominant disorder with male sparing. Nat Genet 1997; 17: 92-95.

20 Moog U: The outcome of diagnostic studies on the etiology of mental retardation: considerations on the classification of the causes. Am J Med Genet A 2005; 137: 228-231.

21 Neri G, Chiurazzi P, Arena F, Lubs HA, Glass IA: XLMR genes: update 1992. Am J Med Genet 1992; 43: 373-382.

22 Neri G, Chiurazzi P, Arena JF, Lubs HA: XLMR genes: update 1994. Am J Med Genet 1994; 51: 542-549.

23 Lubs HA, Chiurazzi P, Arena JF, Schwartz C, Tranebjaerg L, Neri G: XLMR genes: update 1996. Am J Med Genet 1996; 64: 147-157.

24 Lubs H, Chiurazzi P, Arena J, Schwartz C, Tranebjaerg L, Neri G: XLMR genes: update 1998. Am J Med Genet 1999; 83: 237-247.

25 Chiurazzi P, Hamel BC, Neri G: XLMR genes: update 2000. Eur J Hum Genet 2001; 9: 71-81.

26 Chiurazzi P, Tabolacci E, Neri G: X-linked mental retardation (XLMR): from clinical conditions to cloned genes. Crit Rev Clin Lab Sci 2004; 41: 117-158.

27 Mulley JC, Kerr B, Stevenson R, Lubs H: Nomenclature guidelines for X-linked mental retardation. Am J Med Genet 1992; 43: $383-391$.

28 Stromme P, Gilfillan G, Selmer KK et al: Mutations in SLC9A6 cause an Angelman syndrome like phenotype. In the Proceedings of the 13th International Workshop on Fragile $X$ and $X$-linked mental retardation, Venice (Italy), 3-6 October 2007, Abstract 15.

29 Marco E, Abidi FE, Bristow J et al: ARHGEF9 disruption in a female patient is associated with $\mathrm{X}$ linked mental retardation and sensory hyperarousal. J Med Genet, September 2007; doi:10.1136/ jmg.2007.052324.

30 Kalscheuer VM, Harvey $\mathrm{K}$, Musante L et al: Truncation of ARHGEF9 encoding the RhoGEF collybistin by a de novo balanced translocation in a severely mentally retarded patient. Abstract 10 . Proceedings of the 13th International Workshop on Fragile $X$ and $X$-linked mental retardation, Venice (Italy), 3-6 October 2007, Abstract 15.

31 Froyen G, Corbett M, Vandewalle $J$ et al: Submicroscopic duplications of the hydroxysteroid dehydrogenase HSD17B10 and the E3 ubiquitin ligase HUWE1 are associated with mental retardation. Am J Hum Genet 2008, in press.

32 Meins M, Lehmann J, Gerresheim F et al: Submicroscopic duplication in Xq28 causes increased expression of the MECP2 gene in a boy with severe mental retardation and features of Rett syndrome. J Med Genet 2005; 42: e12.

33 Van Esch H, Bauters M, Ignatius J et al: Duplication of the MECP2 region is a frequent cause of severe mental retardation and progressive neurological symptoms in males. Am J Hum Genet 2005; 77: 442-453. 
mental retardation and multiple congenital anomalies: a new series of 140 patients and review of published reports. J Med Genet 2006; 43: 625-633.

49 Lugtenberg D, de Brouwer AP, Kleefstra T et al: Chromosomal copy number changes in patients with non-syndromic $\mathrm{X}$ linked mental retardation detected by array CGH. J Med Genet 2006; 43: $362-370$.

50 Friedman JM, Baross A, Delaney AD et al: Oligonucleotide microarray analysis of genomic imbalance in children with mental retardation. Am J Hum Genet 2006; 79: 500-513.

51 Zhang L, Jie C, Obie C et al: X chromosome cDNA microarray screening identifies a functional PLP2 promoter polymorphism enriched in patients with X-linked mental retardation. Genome Res 2007; 17: 641-648.

52 van Karnebeek CD, Scheper FY, Abeling NG et al: Etiology of mental retardation in children referred to a tertiary care center: a prospective study. Am J Ment Retard 2005; 110: 253-267.

53 Curry CJ, Stevenson RE, Aughton D et al: Evaluation of mental retardation: recommendations of a Consensus Conference: American College of Medical Genetics. Am J Med Genet 1997; 72: $468-477$.

54 Moeschler JB, Shevell M, the American Academy of Pediatrics Committee on Genetics: Clinical genetic evaluation of the child with mental retardation or developmental delays. Pediatrics 2006; 117: $2304-2316$.

55 Battaglia A, Carey JC: Diagnostic evaluation of developmental delay/mental retardation: an overview. Am J Med Genet C 2003, 117: $3-14$.

56 van Karnebeek CD, Jansweijer MC, Leenders AG, Offringa M, Hennekam RC: Diagnostic investigations in individuals with mental retardation: a systematic literature review of their usefulness. Eur J Hum Genet 2005; 13: 6-25.

57 Mandel JL, Chelly J: Monogenic X-linked mental retardation: is it as frequent as currently estimated? The paradox of the ARX (Aristaless X) mutations. Eur J Hum Genet 2004; 12: 689-693.

58 de Brouwer AP, Yntema HG, Kleefstra $\mathrm{T}$ et al: Mutation frequencies of $\mathrm{X}$-linked mental retardation genes in families from the EuroMRX consortium. Hum Mutat 2007; 28: 207-208.

59 Battaglia A: Neuroimaging studies in the evaluation of developmental delay/mental retardation. Am J Med Genet C 2003; 117: $25-30$.

60 Kahler SG, Fahey MC: Metabolic disorders and mental retardation. Am J Med Genet C 2003; 117: 31-41.

61 Clark AJ, Rosenberg EH, Almeida LS et al: X-linked creatine transporter (SLC6A8) mutations in about $1 \%$ of males with mental retardation of unknown etiology. Hum Genet 2006; 119: 604-610.

Supplementary Information accompanies the paper on European Journal of Human Genetics website (http://www.nature.com/ejhg) 